\title{
CRIANÇAS, DOCÊNCIAS, LEITURA E ESCRITA: notas sobre o Pacto Nacional pela Alfabetização na Idade Certa (PNAIC)
}

Mariane Éllen da Silva*

Myrtes Dias da Cunba**

Resumo: O presente texto socializa algumas reflexões sobre o PNAIC e tem por objetivo compreender como esse Programa representa as crianças e seus aprendizados sobre a leitura e a escrita no $1^{\circ}$ ano do Ensino Fundamental. Este escrito faz parte de uma pesquisa documental e por meio de análise da configuração textual de Cadernos deste Programa, utilizados na formação continuada de professores alfabetizadores, evidenciou uma fragmentação das linguagens oral e escrita e uma quase ausência de outras linguagens que compõem o cotidiano das crianças.

Palavras-chave: Ensino fundamental. Infâncias. Crianças. Docências. Leitura e escrita.

\section{CHILDREN, TEACHING, READING AND WRITING: notes on the Pacto Nacional pela Alfabetização na Idade Certa (PNAIC)}

\begin{abstract}
This text presents some reflections on understanding the PNAIC's purpose for children and their reading and writing learning processes in the first year of elementary school. This paper is part of a documental research which analyzed the textual configuration of notebooks used for teacher's training and whose results demonstrated that the PNAIC's material emphasized oral language and written language like a separated process as also the absence of other multiples languages that are part of the children's daily lives.
\end{abstract}

Key words: Elementary school. Childhood. Children. Teaching. Reading and writing.

\footnotetext{
* Mestre em Educação pela Universidade Federal de Uberlândia (UFU). Professora da área de Alfabetização Inicial da Escola de Educação Básica da Universidade Federal de Uberlândia (CAp ESEBA-UFU). E-mail: mariane.eseba@ufu.br

** Doutora em Educação pela Universidade Estadual de Campinas (UNICAMP). Professora do curso de Pedagogia e do Programa de Pós-Graduação da Faculdade de Educação da Universidade Federal de Uberlândia (FACED-UFU). E-mail: myrtesufu@gmail.com
} 


\section{Introdução}

O processo de alfabetização apresenta-se como assunto central no contexto educacional atual; trata-se de uma das prioridades do governo federal em âmbito nacional, tendo em vista que no ano de 2012 foi implementado pelo governo, em parceria com as universidades públicas brasileiras, secretarias de educação e municípios, o PNAIC (Pacto Nacional pela Alfabetização na Idade Certa), com o objetivo de assegurar que todas as crianças estejam alfabetizadas até os 8 anos de idade, ao final do $3^{\circ}$ ano do Ensino Fundamental. O PNAIC é uma política pública nacional voltada para a formação de professores alfabetizadores que atuam no $1^{\circ}, 2^{\circ}$ e $3^{\circ}$ anos do Ensino Fundamental e também nas classes multisseriadas.

Realizar um estudo sobre o PNAIC na formação de professores alfabetizadores oportunizou-nos formular uma compreensão sobre as perspectivas e os possíveis impasses desse programa no tocante ao processo de formação continuada de professores, práticas docentes e também sobre as concepções de criança e de seu aprendizado, especialmente, no $1^{\circ}$ ano do ensino fundamental.

Por meio de seus 24 Cadernos de Formação ${ }^{1}$ apresenta um caminho metodológico para se alfabetizar até os 8 anos de idade. Em cada componente curricular (Língua Portuguesa, Matemática, História, Geografia, Ciências e Arte) do ciclo de alfabetização, constituído pelo $1^{\circ}, 2^{\circ}$ e $3^{\circ}$ anos do Ensino Fundamental, desenvolve-se uma dinâmica em que cada assunto é ensinado de acordo com uma orientação que varia como "introduzido (I)", "aprofundar (A)" e "consolidar (C)". Todo o trabalho de alfabetização apresentado nesse Programa funda-se no chamado "direito de aprendizagem" da criança. Assim, preocupamo-nos em investigar o que estava sendo direcionado para professores ensinarem e para crianças aprenderem em termos de leitura e escrita. Precisávamos compreender o que esse direito de aprender significava e se as ações educativas indicadas nos Cadernos, fundamentadas neste direito de aprender, sugeriam mudanças na compreensão e organização do tempo escolar e na compreensão das infâncias, especialmente para as crianças do $1^{\circ}$ ano. Diante dessas questões, nosso objetivo no presente texto é compreender de que maneira o PNAIC projeta a criança e seu aprendizado da leitura e escrita no $1^{\mathrm{o}}$ ano do Ensino Fundamental.

De acordo com os propósitos da investigação desenvolvida, optamos por realizar uma pesquisa documental por a considerarmos como uma possibilidade para ampliar e aprofundar nosso olhar frente às diferentes faces do objeto a ser investigado. Juntamente com a pesquisa documental (leis, decretos e Cadernos da formação do PNAIC) desenvolvemos uma ampla busca e análise de trabalhos acadêmicos que explorassem a temática em questão.

A opção por realizar uma análise sobre como a criança e seu aprendizado da leitura e escrita são

\footnotetext{
${ }^{1}$ São 8 Cadernos para cada ano de ensino e abordam os seguintes temas: Unidade 1 Currículo; Unidade 2 Planejamento; Unidade 3 Sistema de Escrita Alfabética; Unidade 4 Brincadeira/lúdico; Unidade 5 Gêneros Textuais; Unidade 6 A relação entre Alfabetização e outras Áreas de Conhecimentos; Unidade 7 Heterogeneidade na sala de aula e Unidade 8 Avaliação.
} 
apresentados no primeiro ano do Ensino Fundamental pelo material do PNAIC constituiu-se com o propósito de aprofundar os conhecimentos a respeito dessa temática, especialmente verificar como a defesa do direito de aprender a ler e escrever das crianças sustentava-se nos livros organizados pelo MEC para formação dos docentes. Para isso buscamos conhecer posicionamentos, conceitos e ideias apresentadas nos Cadernos, verificamos sua coerência interna (os Cadernos compartilham entre si posicionamentos, conceitos e ideias sobre crianças, ensino-aprendizado, leitura e escrita e formação de professores? Quais são esses posicionamentos, conceitos e ideias?) e os confrontamos com conceitos e debates correntes no meio educacional nos dias de hoje, especialmente, as noções de que crianças são sujeitos históricos que se constituem na relação com outros sujeitos, que o processo de constituição das crianças caracteriza-se por um processo de ensinar-aprender articulado por múltiplas linguagens (corporal, gestual, artística, musical, simbólicas, dentre outras), destacando-se nesse processo a dimensão lúdica, as brincadeiras e os jogos; que o processo de ensinar-aprender a ler e escrever não pode ser transformado em um simples objeto escolar, pois se constitui num complexo sistema social de representação, comunicação e expressão (VIGOTSKI, 2009; 2000); que os professores alfabetizadores para ensinarem as crianças a ler e a escrever necessitam ser reconhecidos e considerados como sujeitos possuidores do direito de ensinar, o que requer ir além do aprender técnicas de ensino e demanda ampla vivência como sujeitos que usufruem e praticam todas as possibilidades das linguagens e que reconhecem as crianças como sujeitos ativos, praticantes de muitas linguagens; daí a compreensão e possibilidade de ensinar a ler e a escrever de acordo com a diversidade de infâncias reais, numa temporalidade que é organizada pela significação social e subjetiva da linguagem escrita e não apenas pela cronologia de anos letivos (RESENDE, 2015; KLEIN, 2011; KRAMER, 2007; ABRAMOVAY; KRAMER, 1985).

\section{Resultados e discussão}

O PNAIC está inserido em um contexto educacional do ensino fundamental de nove anos, o que significa a entrada de crianças com seis anos nesse nível de ensino. A concepção de ensino e aprendizagem da leitura e escrita para as crianças do $1^{\circ}$ ano e sua relação com o tempo da infância nesse contexto foi estudada por Kramer (2007) e Klein (2011), pesquisas que sinalizaram para a necessidade de se (re)construir um currículo escolar para tais crianças, com conexões e desdobramentos para o ensino fundamental como um todo. No atual cenário educacional, o PNAIC consistiu num programa de formação continuada para os professores alfabetizadores brasileiros e apresentou uma matriz curricular para as séries iniciais do ensino fundamental fundada no direito de aprendizagem da criança e objetiva que todas as crianças brasileiras sejam alfabetizadas até os 8 anos, considerada como idade certa para a alfabetização.

A maioria de autores que participaram da produção do material para o Programa - especialmente os Cadernos destinados à formação de professores em língua portuguesa no ano de 2013 - é da 
Universidade Federal de Pernambuco (UFPE) e desenvolvem pesquisas sobre alfabetização, letramento, leitura, produção de textos e didática do ensino da língua portuguesa. Os Cadernos de alfabetização em língua portuguesa foram organizados para favorecer o desenvolvimento do trabalho da formação continuada com o professor alfabetizador e contêm textos teórico-conceituais, exemplos de práticas pedagógicas, sugestões de atividades de ensino a partir de jogos, livro didático, sugestões de leituras adicionais para que os professores reflitam sobre suas ações, construam práticas e as relacionem com os aportes teóricos fornecidos. A conexão entre textos e seções que compõem tais Cadernos fundamentase em conceitos defendidos pelos autores, tais como, por exemplo: alfabetização na perspectiva do letramento, direitos de aprendizagem para cada componente curricular objetivando introduzir, aprofundar e consolidar conhecimentos, capacidades e atitudes, além de indicar a utilização de recursos didáticos repassados pelo Ministério da Educação às escolas, por exemplo, jogos para o processo de alfabetização, livros literários adquiridos no PNBE, livros didáticos aprovados no PNLD, obras complementares adquiridas no PNLD, coleção de obras pedagógicas disponíveis no portal do professor, dentre outros.

A proposta metodológica da formação docente no PNAIC centra-se na perspectiva de promover estudos e reflexões e principalmente experiências práticas sobre a alfabetização para os professores, buscando com essa formação favorecer a aprendizagem das crianças. Sobre esse aspecto, acreditamos que o processo de formação continuada que busca relacionar um desempenho docente satisfatório e a obtenção de qualidade educacional para a escola pública deve ser ampliado, de modo a não se limitar a um conjunto de práticas estritamente escolares para solucionar problemas históricos, sociais e estruturais da educação brasileira. Desta forma, faz-se necessário considerar as dimensões históricas, políticas, econômicas e culturais, especialmente para os anos iniciais do ensino fundamental, que configuram a profissão docente. Quando isso não acontece, a responsabilidade pela qualidade da educação torna-se dever do professor, excluindo ou minimizando, assim, a responsabilidade do sistema público de educação em garantir, por exemplo, valorização social e salarial para os profissionais da educação, provimento e manutenção de infraestrutura física e pedagógica adequada para as escolas, organização de propostas curriculares com a participação dos professores, gestão democrática, entre outras medidas.

Os professores, dessa forma, por mais que se escreva o contrário nos Cadernos, são considerados executores de propostas produzidas por professores e pesquisadores que instrumentalizam a prática do professor por meio de teorias e técnicas que visam à resolução de problemas imediatos, caracterizando o ensino como um processo técnico de transposições didáticas.

Buscando compreender como o PNAIC orienta o ensino e aprendizado da leitura e escrita e como a criança é vista nesse processo, identificamos que esse Programa sinaliza e se fundamenta, dentre outros conceitos, no "direito(s) de aprendizagem” das crianças. Tais direitos de aprendizagem aparecem relacionados com os componentes curriculares de Língua Portuguesa, Matemática, História, Geografia, Ciências e Artes que são contemplados no ciclo da alfabetização. 
Nossas análises sobre leitura e escrita, bem como a caracterização dos direitos de aprendizagens em Língua Portuguesa no âmbito do primeiro ano do Ensino Fundamental, deu-se a partir dos cinco eixos apresentados pelo PNAIC: 1- leitura; 2- produção de textos escritos; 3- oralidade; 4- análise linguística: discursividade, textualidade e normatividade; 5- análise linguística: apropriação do Sistema de Escrita Alfabética (SEA); os processos de ensino e os tempos de aprendizagem da leitura e escrita.

Para cada um desses eixos, os Cadernos do PNAIC apresentam quadros de direitos de aprendizagem que delimitam conhecimentos, capacidades e atitudes a serem desenvolvidos com as crianças no decorrer do $1^{\circ}, 2^{\circ}$ e $3^{\circ}$ anos do ensino fundamental, de modo a introduzir, aprofundar e consolidar os conteúdos determinados, os quais contemplariam o que se espera que o professor ensine para que o estudante aprenda; cada eixo estabelece também o que as crianças têm como direito de aprender, de modo geral e específico em cada ano do ciclo de alfabetização. Diante disso, afirma-se que "para garantir que todas as crianças aprendam a ler e escrever, faz-se necessário traçar direitos de aprendizagem que possam nortear a organização do trabalho pedagógico nas escolas" (BRASIL, 2012a, p.05).

Verificamos que essa organização de aprendizagens previstas pelo PNAIC apresenta um caminho metodológico que, para garantir os direito das crianças em relação aos conhecimentos, as habilidades e atitudes no processo de alfabetização, estipula um tempo cronológico para os aprendizados correspondentes; transformando o conhecimento e a aprendizagem num processo linear, cumulativo, gradual e fragmentado, movimento que pode ser questionados quando se entende que o foco central nesse caso é o aprendizado da língua portuguesa como complexo sistema social simbólico de comunicação e expressão.

Nessa perspectiva, buscando facilitar ou concretizar o aprendizado docente sobre o objeto a ser ensinado às crianças, a língua apresenta-se fragmentada nos eixos de aprendizagem; o que é feito visando à otimização e operacionalização dos processos de alfabetização e letramento em um tempo que se pretende que sejam objetivamente demarcados, tempo que é traduzido em termos do trabalho docente como introduzir, aprofundar e consolidar conhecimentos que garantam o cumprimento de um pacto, um pacto que na prática exclui seus sujeitos, as crianças e os professores, pois não os concebe como sujeitos (diferentes!) que se constituem numa relação histórica, social e humana.

Em sua pesquisa sobre as concepções de linguagem, escrita e alfabetização no PNAIC, Resende (2015, p. 111) analisou os pressupostos linguísticos a respeito desse Programa e especialmente 2 de seus eixos: o da Análise linguística: discursividade, textualidade e normatividade e o da Análise linguística: apropriação do sistema de escrita alfabética; em seu trabalho constatou que:

É consensual a pertinência desses conhecimentos no processo de apropriação da linguagem escrita pelas crianças, se forem forjados na confluência da discursividade, textualidade e normatividade. Entretanto, na proposta de estudo para a compreensão da língua do Programa, prevalece o princípio da 'normatividade', visto a ênfase nas 
convenções ortográficas, fonográficas, (ir)regularidades das palavras, o que dificulta o desenvolvimento discursivo pelas crianças. Assim, a aprendizagem da língua escrita pela criança centra-se na língua-padrão, nas normas e convenções linguísticas, nas características externas dos gêneros do discurso, na ênfase da correspondência grafofônica das palavras, delineando, assim, arbitrariamente a unicidade de significação. Isso implica desconsiderar a natureza plural, dialógica/discursiva da própria palavra no texto a partir dos interlocutores e do contexto social (RESENDE, 2015. p. 111).

Desta forma, a proposta do PNAIC para a língua escrita "restringe os elos de sentidos, ao enfatizar a significação, o idêntico da pronúncia, da forma. E evita o movimento provisório e inacabado da escolha das letras, das palavras, impossibilitando a experiência de leitor e escritor por parte das crianças” (RESENDE, 2015, p. 112). Sendo assim, o pressuposto de língua no arcabouço do PNAIC é de uma "[...]concepção puramente mecanicista da necessidade no domínio da língua" (BAKHTIN/VOLOCHÍNOV, 1995. p. 109).

Verificamos que a proposta do PNAIC disponibiliza aos professores uma matriz curricular que organiza os tempos escolares, dosando a aprendizagem das crianças de modo a introduzir, aprofundar e consolidar em cada uma delas e durante os três primeiros anos do ensino fundamental as capacidades e os conhecimentos referentes ao componente curricular da língua portuguesa. Nesse sentido, o formato desse Programa é totalmente prescritivo, orientado por uma pedagogia que normatiza a linguagem, um modelo educativo que busca desenvolver o ensino visando a uma aprendizagem controlada e marcada por níveis de conhecimento de acordo indiretamente com as idades das crianças, mesmo quando menciona poucas vezes de maneira direta a questão da idade cronológica das crianças.

Diante desse Programa, constatamos também uma concepção de aluno ideal, uma criança hipotética e modelar que transitará num ciclo cronológico de alfabetização determinado previamente, perfazendo seu caminho de aprendizagem ano após ano, concretizando o que se determinou como seu direito de aprender.

Aos professores alfabetizadores requer-se que organizem um planejamento a partir dos cinco eixos da língua portuguesa apresentados pelo PNAIC por meio de sequências didáticas, projetos didáticos, jogos pedagógicos, contemplando a alfabetização na perspectiva do letramento e possibilitando o avanço nas aprendizagens da linguagem oral e escrita pelas crianças. Para obtenção de tal objetivo, os docentes devem aprender a organizar e favorecer ações pedagógicas que permitam às crianças, gradativamente, se alfabetizarem até o $3^{\circ}$ ano do Ensino Fundamental; por mais que o PNAIC sugira esse caminho metodológico, objetivamente apresentado em termos das ações introduzir/aprofundar/consolidar, como possibilidade para a alfabetização, paralelamente deixa subentendido que as crianças têm o dever de consolidar, num determinado tempo escolar, os direitos de aprendizagem apresentados no currículo proposto. As práticas docentes previstas, exemplificadas e incentivadas nos Cadernos do Programa estão voltadas para uma tentativa hegemônica e pretensamente objetiva de organizar o trabalho educativo de forma sistemática e paulatina, por meio de uma regulação e escansão dos tempos de aprendizagem das crianças. Como se o que faltasse para o sucesso do trabalho 
escolar de alfabetização fosse a objetividade de conhecimentos e a organização objetiva do currículo e das atividades educativas.

Nessa perspectiva, os direitos de aprendizagem das crianças preconizados pelo PNAIC em seus Cadernos podem ser interpretados como deveres de aprendizagens, os quais também subentendem deveres de ensinar para os professores, na medida em que sinalizam tanto o que ensinar e como desenvolver as práticas educativas, quanto o que devem as crianças aprender.

Acreditamos que a aprendizagem da leitura e da escrita é construída pela criança em meio aos inúmeros fatores culturais e de acordo com a forma singular com que vivencia esse processo. A escola não tem como negar, transformar ou impedir tal condição. Ao contrário a escola trabalha imersa nessa condição. Portanto, o aprendizado da criança não pode ser considerado ou analisado apenas como uma habilidade a ser adquirida por meio de um ensino regulado de fora da escola, por mais competentes que sejam os formuladores da proposta e das metodologias preconizadas. Ademais, aprender possibilita transformações nas crianças por meio das suas relações com a cultura, isso não significa, em hipótese alguma, que as mudanças serão as mesmas para todos os envolvidos, pelo contrário, cada criança vai construindo seu caminho e se constituindo de forma única através das relações que estabelece, no movimento das relações sociais.

Com base na perspectiva histórico-cultural que assumimos é preciso considerar a complexidade que envolve o aprendizado da leitura e da escrita e o seu caráter subjetivo, reconhecendo que o brincar, a imaginação, o faz de conta, as multidimensionalidades das linguagens e das relações humanas constituem elementos essenciais do aprender. Nesse sentido, a aprendizagem da leitura e escrita não diz respeito apenas ao aprendizado da escrita de letras e palavras e não se limita às relações entre som e letra, mas, sobretudo requer processos relacionais/sociais, culturais, afetivos e cognitivos que corroboram sua materialização.

O direito de a criança aprender e do professor de formar-se continuamente é expresso no PNAIC como uma necessidade dos sujeitos envolvidos e um dever do Estado. Sendo assim, o direito se apresenta entrelaçado com o intuito político-social, corroborando para que os envolvidos na prática educacional se adequem a elas naturalmente, sem divergência/desacordo, ou seja, garantir que os direitos de aprendizagem sejam efetivados e garantir as condições do trabalho docente, por meio da formação continuada, é apresentado como consenso e resultante de um pacto harmônico e natural.

Além disso, utiliza-se um discurso que não se diz fechado, mas apresenta-se acabado quando por meio de um currículo estático universaliza os tempos de aprendizagem de todas as crianças, quando não aborda as complexidades da escola e considera os sujeitos, seja professor ou aluno, sem incluí-los em um contexto histórico-social. De acordo com tal proposição os problemas de aprendizagem ou de formação docente se apresentam como meros indicativos de capacidades estranhas ou inadequadas a um modo correto e adequado de ser e estar no mundo. 
Sob essas circunstâncias, como oportunizar espaços-tempos escolares para se respeitar os tempos das infâncias, desvelando a pluralidade de linguagens em um processo de escolarização e de práticas pedagógicas voltadas para o alfabetizar na idade certa? Interrogar o programa seria um passo inicial para problematizar tal questão e expandir o diálogo, de modo a rever as práticas e concepções que regem o processo de escolarização das crianças, bem como o contexto de produção das infâncias no espaçotempo escolar.

A partir do momento em que analisamos os direitos de aprendizagem em língua portuguesa, buscamos identificar no material do PNAIC como esse programa constrói ou preconiza a organização do cotidiano escolar nas turmas de $1^{\circ}$ ano do ensino fundamental e também compreender como a organização do espaço-tempo de aprender nessa proposta concebe a criança e suas singularidades no processo de ensinar-aprender.

Nesse sentido, identificamos que a perspectiva para a qual conduz o material analisado é o planejamento do processo de alfabetização e ensino/aprendizagem da língua portuguesa, voltado exclusivamente para os eixos direcionadores da língua (leitura; produção de textos; oralidade; análise linguística: discursividade, textualidade e normatividade; análise linguística: apropriação do sistema de escrita alfabética) como orientação estruturante para o planejamento escolar.

No planejamento do ensino com o objetivo de organizar as ações a serem empreendidas durante o ano letivo em turmas do $1^{\circ}$ ano do ensino fundamental sobressai o trabalho com os diferentes eixos da língua portuguesa. Por exemplo: No eixo leitura, os usos que fazemos em nossas práticas sociais de letramento devem ser tomados como base para o ensino e o trabalho na sala de aula com a leitura; no eixo produção de texto o professor deverá promover situações comunicativas para as crianças terem o que dizer e a quem dizer, incentivando a formação da criança produtora de textos para buscar estratégias de escritas. Um exemplo para esse eixo seria as crianças serem incentivadas a escreverem "do jeito que acham que é"; o eixo oralidade aborda a importância de as crianças serem sujeitos capazes de expor, argumentar, explicar, narrar, além de escutar atentamente e opinar, respeitando a vez e o momento de falar; no eixo análise linguística: apropriação do sistema de escrita alfabética deve-se pensar sobre a língua, que possui regras próprias de funcionamento, exigindo conhecimento de sua natureza linguística e de sua estrutura.

É notório que o trabalho pedagógico da linguagem oral e escrita com as crianças precisa ser planejado, discutido, articulado dentro e para fora do espaço escolar, mas, planejar os processos de alfabetização para as crianças do $1^{\circ}$ ano implica planejar sobre os eixos de ensino da língua, de modo a delimitar tempos e espaços de ensino e aprendizagem enfatizando prioritariamente conhecimentos linguísticos, técnicos e escolares da língua portuguesa? Como não envolver ou mencionar em um currículo de $1^{\circ}$ ano a vivência com outras linguagens, por exemplo, as linguagens artísticas e corporal? Nessa análise, buscamos problematizar tais questões afim de produzir conhecimentos acerca dos limites e das possibilidades das proposições contidas no PNAIC, reafirmando a importância da pluralidade de 
linguagens na vida das crianças e do rompimento com posturas que se fundamentam em dosagens do que ensinar e do que aprender no tempo considerado certo, conceitos e posturas que universalizam as práticas pedagógicas e lhes retira infinitas possibilidades de saberes e fazeres no cotidiano escolar.

Outro eixo de análise se voltou para as rotinas da escola, da sala de aula, da criança, buscando estabelecer relações com o espaço-tempo de aprender. Identificamos no material do PNAIC, como se deu a organização do cotidiano escolar nas turmas de $1 .^{\circ}$ ano do ensino fundamental, e buscamos compreender como a organização do espaço-tempo de aprender, nessa proposta, concebeu a criança e suas singularidades.

O caderno da Unidade 2 Ano 1, "Planejamento escolar: alfabetização e ensino da língua portuguesa" afirma que o desafio enfrentado pelos professores para as crianças vivenciarem os eixos da língua como práticas relevantes e interessantes, poderá ser vencido se "o trabalho didático é organizado levando em conta os textos que circulam entre diversos grupos sociais, no dia a dia." (KLEIMAN, 2005, p. 34 apud BRASIL, 2012b, p. 8). Ainda sobre esse aspecto, defende-se que o ensinar voltado para os usos dos gêneros textuais, “[...] significa promover um ensino voltado para a vida, que propicie verdadeiramente a formação do cidadão participativo das práticas sociais que envolvem a cultura escrita. É um direito de nossos alunos e cabe aos professores garantir este direito de aprendizagem a cada um.” (BRASIL, 2012b, p. 08).

Utilizar os gêneros textuais em sala de aula é um recurso que viabiliza conhecer, criar e partilhar inúmeras possibilidades do trabalho com os gêneros devido a sua diversidade e importância na convivência social. Entretanto, o desafio de uma aula prazerosa, significativa, em uma turma de alfabetização, com crianças de seis anos, vai muito além da proposta de conhecimentos sobre a língua portuguesa apresentados a partir do uso dos gêneros textuais, diz respeito também, às diversas relações que são estabelecidas entre as crianças, ao respeito às singularidades infantis, a organização do tempo no espaço educacional direcionada para o desenvolvimento e a aprendizagem das crianças, por isso é imprescindível garantir, na rotina escolar, por exemplo, tempo e espaço para o brincar. Nesse sentido, investigamos como o PNAIC orienta em sua proposta de formação docente a organização das rotinas no cotidiano escolar.

O PNAIC defende a construção de rotinas que possibilitem aos professores desenvolver e diversificar atividades no cotidiano escolar, para que os alunos "possam interagir com diferentes textos ao mesmo tempo em que eles são levados a refletir sobre o Sistema de Escrita Alfabética" (BRASIL, 2012b, p. 20).

Desse modo, defendemos que a organização e a sistematização do trabalho pedagógico é muito importante para a aprendizagem dos alunos. A construção de uma rotina escolar que contemple os diferentes eixos de ensino da língua, por meio de um planejamento elaborado com base na realidade de cada aluno e escola, pode favorecer a realização de atividades que ajudem a promover a autonomia e a criatividade dos alunos no mundo da leitura e da escrita (BRASIL, 2012b, p. 20). 
A partir dessa defesa do PNAIC em relação ao planejamento e à organização das rotinas constatamos um movimento duplo e ambíguo, o qual produz incerteza e imprecisão conceitual para os docentes, mas também, possivelmente, estimula a ausência ou fragilidade de conexões entre o pensar e o fazer de professores. Caso o que se pretenda seja formar professores críticos, criativos e autores de seus trabalhos pedagógicos, entendemos ser importante informar e esclarecer posicionamentos históricos e epistemológicos presentes na história da educação e no trabalho de alfabetizar, pois é o debate sobre diferentes posturas e visões que prevaleceram ao longo da história é que possibilita que professores possam contribuir com a materialização do direito de aprender das crianças.

Identificamos em nossas análises que, por um lado, critica-se com veemência as abordagens positivistas das ciências para a organização do trabalho pedagógico, uma vez que essas se sustentam pela psicologia comportamentalista e pelo tecnicismo no planejamento das rotinas, mas por outro, afirma-se que a partir do trabalho com os eixos estruturantes para o ensino da língua promover-se-á a criatividade e autonomia dos alunos em seus processos de leitura e escrita, tornando práticas de alfabetização diferentes das que eram realizadas anteriormente, porém, nessa proposta de trabalho fragmenta-se a compreensão da língua portuguesa em eixos de ensino, delimitando de maneira predominantemente técnica aos docentes o que e como fazer.

O discurso apresentado no caderno da unidade 2, ano 1, materializa-se nas palavras de Telma Leal as quais são apresentadas no referido caderno, quando essa autora defende a importância do planejamento para a vida escolar, tendo em vista que,

[...] as rotinas escolares asseguram que alguns "procedimentos" básicos sejam "acordados" entre professor e alunos e que os mesmos já se disponibilizem dentro do espaço temporal e espacial para as tarefas pedagógicas. As crianças aprendem, através dessas rotinas, a prever o que fará na escola e a organizar-se. Por outro lado, a existência dessas rotinas possibilita ao professor distribuir com maior facilidade as atividades que ele considera importantes para a construção de conhecimentos em determinado período, facilitando o planejamento diário das atividades didáticas (BRASIL, 2012b, p. 19-20).

Concordamos com as considerações de Leal (BRASIL, 2012b) na medida em que as rotinas assegurem uma organização do tempo e espaço escolar. Entretanto, Proença (2004) alerta-nos para um fator ideológico que a rotina também assume: o espaço-tempo de aprender a partir das atividades e dos encaminhamentos propostos no processo de ensino e aprendizagem envolve uma razão que se sustenta por meio das prioridades e opções estabelecidas no fazer pedagógico.

A rotina estruturante é como uma âncora do dia-a-dia, capaz de estruturar o cotidiano por representar para a criança e para os professores uma fonte de segurança e de previsão do que vai acontecer. Ela norteia, organiza e orienta o grupo no espaço escolar, diminuindo a ansiedade a respeito do que é imprevisível ou desconhecido e otimizando o tempo disponível do grupo. É um exercício disciplinar a construção da rotina do grupo, que envolve prioridades, opções, adequações às necessidades e 
dosagem das atividades. A associação da palavra âncora ao conceito de rotina pretende representar a base sobre a qual o professor se alicerça para poder prosseguir com o trabalho pedagógico (PROENÇA, 2004, p.13, grifos nossos).

Questionamos a postura apresentada no caderno em análise e as palavras de Leal (BRASIL, 2012b, p. 19-20) quanto à ausência da explicitação de que prioridades e opções docentes não são meramente técnicas, mas também políticas. Para exemplificar sua concepção sobre prioridades e opções acerca da rotina, o caderno analisado traz um exemplo de uma professora do $1^{\circ}$ ano do Ensino Fundamental que atua em escola municipal da cidade do Recife/PE. A professora relata como contempla regularmente em sua rotina "as atividades permanentes, sequências didáticas, projetos didáticos, uso do livro didático (dos componentes curriculares Língua Portuguesa e Matemática) e jogos relacionados à área de linguagem (como os jogos distribuídos pelo MEC) e a outros conteúdos." (BRASIL, 2012b, p. 21). No quadro a seguir, apresenta-se no Caderno da Unidade 2, Ano 1, a rotina de trabalho de uma semana dessa professora: 


\begin{tabular}{|c|c|c|c|c|}
\hline $\begin{array}{l}\text { SEGUNDA-FEIRA } \\
\text { Dia } 28 / 05\end{array}$ & $\begin{array}{l}\text { TERÇA-FEIRA } \\
\text { Dia 29/05 }\end{array}$ & $\begin{array}{l}\text { QUARTA-FEIRA } \\
\text { Dia 30/05 }\end{array}$ & $\begin{array}{l}\text { QUINTA-FEIRA } \\
\text { Dia 31/05 }\end{array}$ & $\begin{array}{l}\text { SEKTA-FEIRA } \\
\text { Dia 01/06 }\end{array}$ \\
\hline $\begin{array}{l}\text { - Música: Bom dia; } \\
\text { - Registro do } \\
\text { tempo, uso do } \\
\text { calendário (dia, } \\
\text { me̊s, ano); } \\
\text { - Contagem dos } \\
\text { alunos; } \\
\text { - Escrita da me- } \\
\text { renda do dia (re- } \\
\text { gistro no quadro } \\
\text { para leitura); } \\
\text { - Registro da rotina; }\end{array}$ & $\begin{array}{l}\text { - Música: Bom dia; } \\
\text { - Registro do } \\
\text { tempo, uso do } \\
\text { calendário (dia, } \\
\text { mês, ano); } \\
\text { - Contagem dos } \\
\text { alunos; } \\
\text { - Escrita da me- } \\
\text { renda do dia (re- } \\
\text { gistro no quadro } \\
\text { para leitura); } \\
\text { - Registro da rotina; }\end{array}$ & $\begin{array}{l}\text { - Música: Bom dia; } \\
\text { - Registro do } \\
\text { tempo, uso do } \\
\text { calendário (dia, } \\
\text { mês, ano); } \\
\text { - Contagem dos } \\
\text { alunos; } \\
\text { - Escrita da me- } \\
\text { renda do dia (re- } \\
\text { gistro no quadro } \\
\text { para leitura); } \\
\text { - Registro da rotina; }\end{array}$ & $\begin{array}{l}\text { - Música: Bom dia; } \\
\text { - Registro do } \\
\text { tempo, uso do } \\
\text { calendário (dia, } \\
\text { mês, ano); } \\
\text { - Contagem dos } \\
\text { alunos; } \\
\text { - Escrita da me- } \\
\text { renda do dia (re- } \\
\text { gistro no quadro } \\
\text { para leitura); } \\
\text { - Registro da rotina; }\end{array}$ & $\begin{array}{l}\text { - Música: Bom dia; } \\
\text { - Registro do } \\
\text { tempo, uso do } \\
\text { calendário (dia, } \\
\text { mês, ano); } \\
\text { - Contagem dos } \\
\text { alunos; } \\
\text { - Escrita da me- } \\
\text { renda do dia (re- } \\
\text { gistro no quadro } \\
\text { para leitura); } \\
\text { - Registro da rotina; }\end{array}$ \\
\hline $\begin{array}{l}\text { Roda de conversa } \\
\text { - conversa sobre } \\
\text { o final de semana; }\end{array}$ & $\begin{array}{l}\text { Leitura deleite/ } \\
\text { Ficha de acom- } \\
\text { panhamento dos } \\
\text { livros lidos no } \\
\text { mês; }\end{array}$ & $\begin{array}{l}\text { Leitura deleite/ } \\
\text { Ficha de acom- } \\
\text { panhamento dos } \\
\text { livros lidos no } \\
\text { mês; }\end{array}$ & $\begin{array}{l}\text { Leitura deleite/ } \\
\text { Ficha de acom- } \\
\text { panhamento dos } \\
\text { livros lidos no } \\
\text { mês; }\end{array}$ & \multirow{2}{*}{$\begin{array}{l}\text { Uso do laborató- } \\
\text { rio de Informá- } \\
\text { tica: Jogos didá- } \\
\text { ticos, de acordo } \\
\text { com as necessi- } \\
\text { dades do grupo } \\
\text { ou relacionada ao } \\
\text { que está sendo } \\
\text { estudado (digitar } \\
\text { palavras ditadas } \\
\text { pela professora): }\end{array}$} \\
\hline $\begin{array}{l}\text { Leitura deleite/ } \\
\text { Ficha de acom- } \\
\text { panhamento dos } \\
\text { livros lidos no } \\
\text { mês; }\end{array}$ & $\begin{array}{l}\text { Roda de leitura: } \\
\text { texto informativo } \\
\text { sobre a extinção } \\
\text { de animais; }\end{array}$ & $\begin{array}{l}\text { Projeto didático: } \\
\text { sustentabilidade } \\
\text { e o lixo, reflexão } \\
\text { sobre a poluiçăo } \\
\text { dos rios que } \\
\text { prejudica o habi- } \\
\text { tat dos animais; }\end{array}$ & $\begin{array}{l}\text { Roda de leitura: } \\
\text { Texto instrucional } \\
\text { sobre a brincadei- } \\
\text { ra das cadeiras, } \\
\text { explicitando as } \\
\text { regras (vivência } \\
\text { da brincadeira no } \\
\text { pátio da escola); }\end{array}$ & \\
\hline $\begin{array}{l}\text { Merenda/Recreio } \\
\text { Cantinho da leitu- } \\
\text { ra (livre); }\end{array}$ & $\begin{array}{l}\text { Merenda/Recreio } \\
\text { Cantinho da leitu- } \\
\text { ra (livre); }\end{array}$ & $\begin{array}{l}\text { Merenda/Recreio } \\
\text { Cantinho da leitu- } \\
\text { ra (livre): }\end{array}$ & $\begin{array}{l}\text { Merenda/Recreio } \\
\text { Cantinho da leitu- } \\
\text { ra (livre): }\end{array}$ & $\begin{array}{l}\text { Merenda/Recreio } \\
\text { Cantinho da leitu- } \\
\text { ra (livre): }\end{array}$ \\
\hline $\begin{array}{l}\text { Roda de leitura: } \\
\text { Texto Jacaré } \\
\text { (João Paulo Paes), } \\
\text { interpretação } \\
\text { textual, destacan- } \\
\text { do a problemática } \\
\text { de animais em } \\
\text { extinção. }\end{array}$ & $\begin{array}{l}\text { LD } \\
\text { Português: (no- } \\
\text { mes, brincadeiras } \\
\text { e letras)-cantiga } \\
\text { de roda: ciranda, } \\
\text { cirandinha, iden- } \\
\text { tificação do nome } \\
\text { dos colegas; }\end{array}$ & $\begin{array}{l}\text { Construçāo de } \\
\text { um mural, a partir } \\
\text { das figuras sele- } \\
\text { cionadas pelos } \\
\text { alunos, destacan- } \\
\text { do características } \\
\text { dos animais (duas } \\
\text { patas, quatro } \\
\text { patas, nenhuma } \\
\text { pata): }\end{array}$ & $\begin{array}{l}\text { LD Matemática: } \\
\text { Brincadeira das } \\
\text { cadeiras, identi- } \\
\text { ficando sucessor } \\
\text { e antecessor dos } \\
\text { numerais, conta- } \\
\text { gem e leitura de } \\
\text { imagens; }\end{array}$ & $\begin{array}{l}\text { Produção textual } \\
\text { coletiva com re- } \\
\text { gistro em ficha; }\end{array}$ \\
\hline $\begin{array}{l}\text { Atividade de } \\
\text { apropriaçăo do } \\
\text { SEA: construção } \\
\text { de palavras, uti- } \\
\text { lizando alfabeto } \\
\text { móvel e regis- } \\
\text { tro no caderno } \\
\text { (dupla). }\end{array}$ & $\begin{array}{l}\text { Jogo didático: } \\
\text { Bingo dos sons } \\
\text { iniciais (apresen- } \\
\text { tação dos jogos, } \\
\text { explicitando as } \\
\text { regras). }\end{array}$ & $\begin{array}{l}\text { Atividade de } \\
\text { apropriação do } \\
\text { SEA: construção } \\
\text { de palavras, uti- } \\
\text { lizando alfabeto } \\
\text { móvel e regis- } \\
\text { tro no caderno } \\
\text { (dupla). }\end{array}$ & $\begin{array}{l}\text { Jogo didático: } \\
\text { Caça-rimas (apre- } \\
\text { sentação dos } \\
\text { jogos, explicitan- } \\
\text { do as regras). }\end{array}$ & $\begin{array}{l}\text { Hora do brinque- } \\
\text { do (carrinhos, bo- } \\
\text { necos, bonecas, } \\
\text { joguinhos). }\end{array}$ \\
\hline
\end{tabular}

Fonte: (BRASIL, 2012b, p. 26).

Ressaltamos que no caderno da unidade 2, ano 1 foi apresentado apenas um exemplo sobre como uma professora organiza sua rotina. Sentimos falta do contraste, das variadas formas de pensar e de construir as práticas pedagógicas. Sabemos que seria impossível esgotar as possibilidades do cotidiano escolar em um caderno, porém, esperávamos um aprofundamento e diversificação de exemplos e de conversas sobre diferentes maneiras de pensar e organizar rotinas escolares com crianças no primeiro ano do Ensino Fundamental.

Constatamos que o foco da rotina apresentada no caderno em questão está voltado para a linguagem oral e escrita e também privilegia vários aspectos que o PNAIC sugere para alfabetizar as 
crianças, por exemplo: um trabalho sistemático com a alfabetização; atividade permanente com a leitura deleite; todos os dias os alunos são levados a refletir sobre as unidades menores das palavras por meio dos gêneros textuais; jogos didáticos voltados para a exploração de rimas, sons iniciais e trabalho com escrita das palavras; utilização do livro didático de língua portuguesa e de matemática; atividades voltadas para o sistema de escrita alfabética (SEA) para que os alunos pensem constantemente sobre a relação som-grafia; nesse material também constatamos uma quase ausência das linguagens artísticas e brincadeiras.

A maneira como esse exemplo de rotina para o $1^{\circ}$ ano do ensino fundamental é apresentado nos inquieta sobremaneira pela ausência de características próprias das crianças nessa faixa etária em relação ao modo de organização do tempo e espaço escolar. Acreditamos que o planejamento de uma rotina escolar envolve como já comentamos anteriormente, prioridades e opções dos docentes, por exemplo, o brincar como atividade inerente à infância, porém, na organização indicada pelo Programa tal atividade é indicada no último horário, do último dia da semana, fato que demonstra uma desvalorização do brincar e um distanciamento das necessidades das crianças. O brincar acaba por se constituir como uma atividade sem importância, na medida em que as crianças devem primeiro realizar todas as outras atividades previstas na rotina escolar.

Analisando especificamente os jogos e as brincadeiras apresentados nessa rotina para o trabalho no primeiro ano do Ensino Fundamental (caderno da unidades 2 ano 1) constatamos que esses também se voltam para o eixo da análise linguística, por exemplo: apropriação do sistema de escrita alfabética e a brincadeira das cadeiras para identificar antecessor e sucessor, tornando-se evidente o caráter restrito e eminentemente funcional dos jogos e brincadeiras, isto é, as brincadeiras e os jogos como ferramentas voltadas para o ensino dos conteúdos (caderno da unidades 4 ano 1).

O caráter lúdico das brincadeiras e dos jogos didáticos se faz presente em vários exemplos apresentados pelos autores dos textos da seção "Aprofundando o tema", bem como pela professora que relatou sua experiência no caderno da unidade 2, Ano 1, segundo essa profissional, com o intuito de tornar o aprendizado prazeroso e significativo para as crianças; entretanto, mesmo existindo discussões, indicações e exemplos da utilização de jogos e brincadeiras no processo de ensino-aprendizagem, identificamos aí uma postura questionável de conceber jogos e brincadeiras voltados estritamente para o ensino da língua portuguesa; a partir de tal constatação, observamos que no PNAIC concebe-se uma função restrita para o brincar; na proposta do PNAIC projeta-se também uma representação restrita e idealizada de criança e de infância.

Inquieta-nos, nesse caso, o lugar restrito da infância no processo educativo tendo em vista que prevalece uma visão adultocêntrica do aprender, valorizando aspectos técnicos da alfabetização em detrimento do reconhecimento da infância como diversidade nos modos de ser, o que se expressa numa necessidade de experimentação com múltiplas linguagens para a concretização do aprendizado escolar das crianças. Delimitar uma rotina para as crianças, em especial para as de 6 anos, requereria contemplar 
na rotina escolar suas singularidades como crianças reais, sujeitos históricos, produtoras de cultura e seus direitos, principalmente o de aprender e de brincar.

Nesse sentido, identificar como formas de brincar, expressões lúdicas e livres das crianças apresentam-se nas rotinas, desvelam posturas e concepções sobre a infância que poderiam ser mais valorizadas no processo educacional, o que requereria além de uma massiva formação docente preconizada no PNAIC, a criação de condições para que escolas pudessem continuar o trabalho iniciado nesse Programa por meio da efetivação de um processo de formação continuada e em serviço de docentes. A rotina que defendemos visualiza, valoriza e trabalha a linguagem oral e escrita, mas, sobretudo, abre-se para o reconhecimento e incorporação de infâncias diversas, de sujeitos sociais diferentes. Sujeitos que se constituem nas relações sociais, na produção da cultura e no brincar. Sujeitos que se expressam de forma plural em múltiplas linguagens.

Sendo assim, na proposta do PNAIC não se incentiva o trabalho docente com outras linguagens, além da língua portuguesa. Uma proposta coerente e significativa de trabalho com as crianças necessita criar meios para que os professores possam promover uma relação significativa entre ensino e aprendizagem, por isso, destacamos a importância de se valorizar as brincadeiras e os brinquedos (o que não consta como material do PNAIC destinados às escolas), os jogos simbólicos, o movimento, as expressões artístico-culturais, tais como teatro, a música e a dança, enfim, trata-se de valorizar as inúmeras manifestações de linguagens e sua incorporação nas práticas de planejamento das atividades escolares diárias.

O trabalho pedagógico no primeiro ano do ensino fundamental caracteriza-se pelo trabalho com as múltiplas linguagens. A aprendizagem da leitura e escrita pode ser compreendida numa outra lógica.

Caso consideremos que a alfabetização envolve uma construção que se constitui por meio de um processo de ensinar e aprender, que não se dá em momentos específicos restritos a escola e a sala de aula e que as múltiplas linguagens se expressam constantemente no trabalho com as crianças, poderemos conceber que uma criança aprende a ler e escrever a partir de suas brincadeiras, de sua imaginação, de suas emoções, de suas relações sociais e culturais. Dessa forma, as atividades planejadas levando em consideração especificidades das crianças “enriquecem as experiências infantis e possuem um significado real para a vida das crianças, elas podem favorecer o processo de alfabetização, quer a nível do reconhecimento e representação dos objetos e das suas vivências, quer a nível de seus pensamentos e afetos.” (ABRAMOVAY; KRAMER, 1985, p. 104). Ainda, de acordo com essas autoras,

Então, se estamos considerando que a alfabetização não se dá em um momento; e sim através de construção, precisamos ter em mente que as formas de representação e expressão do e sobre o mundo vão se diversificando, aos poucos, e se tornando mais complexas: de início são motoras e sensoriais (aparecem basicamente como ação); em seguida, simbólicas (aparecem como imitação, dramatização, construção, modelagem, reconhecimento de figuras e símbolos, desenho, linguagem); posteriormente são codificadas (aparecem como leitura e escrita). Compreender que a alfabetização tem esse caráter dinâmico de construção, significa, então, compreender que os mecanismos 
da leitura e da escrita se constituem numa parte integrante do processo, que se beneficia se são exploradas as etapas anteriores. Quanto mais forem, portanto, trabalhadas as formas de representação e expressão sensoriais, motoras e simbólicas, mas se estará contribuindo para a aprendizagem específica da linguagem escrita (ABRAMOVAY; KRAMER, 1985, p. 104).

Diante do que analisamos a partir do material produzido para o PNAIC observamos que compreender as crianças - considerando processos sociais que caracterizam sua vida e processos singulares de compreensão, diferentes culturas, suas capacidades físicas, cognitivas, estéticas, éticas, expressivas e emocionais - continua sendo um desafio para a alfabetização, o qual foi parcialmente enfrentado pelo Programa.

Permanece sendo grande desafio para educadores e escolas a produção de práticas pedagógicas que valorizem, cotidianamente, em suas rotinas, a imaginação infantil, o brincar, os diversos saberes e as múltiplas linguagens, com o propósito de produzir espaços lúdicos e culturais na aprendizagem das crianças do $1 .^{\circ}$ ano do ensino fundamental.

Para tanto, a superação de rotinas, mecanizadas e estereotipadas, e a valorização do ponto de vista das especificidades infantis tornam-se pertinentes à medida que favorecem ação pedagógica respaldada em visão integrada do desenvolvimento infantil, respeitando peculiaridades das crianças e oportunizando, de fato, situações de aprendizagem significativas e prazerosas:

Brincar é, sem dúvida, uma forma de aprender, mas é muito mais que isso. Brincar é experimentar-se, relacionar-se, imaginar-se, expressar-se, compreender-se, confrontarse, negociar, transformar-se, ser. Na escola, a despeito dos objetivos do professor e de seu controle, a brincadeira não envolve apenas a atividade cognitiva da criança. Envolve a criança toda. É prática social, atividade simbólica, forma de interação com o outro. Acontece no âmago das disputas sociais, implica a constituição do sentido. É criação, desejo, emoção, ação voluntária (FONTANA; CRUZ, 1997, p. 139).

Por isso, torna-se imprescindível garantir, na rotina escolar, de todas as crianças, tempo e espaço para brincar. O brincar, entendido aqui não como recurso pedagógico, mas, sim, como prática inerente à infância, e que se constitui de múltiplas linguagens. Identificamos, portanto, que, por mais que o PNAIC tente combater e criticar visões e práticas educativas tecnicistas, prevalecem, em suas orientações, a visão e o incentivo para a criação de rotina escolar predominantemente tecniscista e tecnicizante, centrada nos eixos estruturantes da língua portuguesa, conduzindo à fragmentação da linguagem.

Considerar o brincar como processo, que constitui o sujeito e sua subjetividade, parte do pressuposto de respeitar a infância e valorizar as crianças como sujeitos que têm voz e vez, sujeitos de direitos, competentes, criativos. Qual concepção de criança está guiando as práticas educativas para a infância?

Conjecturamos, na contramão dessa perspectiva, que disciplina e didatiza o brincar, outros modos de pensar os processos de escolarização na alfabetização inicial, envolvendo, nessa dimensão, espaços e tempos para a vivência das múltiplas linguagens, alargando o tempo das experiências em linguagens da 
criança. Tal tempo não se refere ao cronológico, linear e evolutivo que limita e fragmenta as aprendizagens destinadas à leitura e à escrita com a pretensão de se alfabetizar na "idade certa". Falamos de um tempo amplificado para as experiências da própria condição de ser criança, um tempo em que a criança, tomada com seu modo de ser e de estar na relação com o mundo, expressa-se nas linguagens, no brincar, em sua inteireza.

Mediante as considerações, acreditamos que devemos repensar os paradigmas de formação docente para a infância, tendo em vista que proposta que atenda à formação social e cultural do professor pode promover uma

Docência que, ao exercer-se, inventa. Reescreve os roteiros rotineiros de outras épocas. Desenvolve a "artistagem" de práticas, que desfazem a compreensão, a fala, a visão e a escuta dos mesmos sujeitos e saberes, dos antigos problemas e das velhas soluções. Dispersam a mesmice e fazem diferença ao educar as diferenças infantis. Uma "artistagem" de ordem poética, estética e política, derivada dos sobressaltos e alegrias de trabalhar nas fronteiras entre disciplinas, os sujeitos e não sujeitos, os sentidos e os sem sentidos. Docência de um artista, que promove o auto-despreendimento, implicado no questionamento dos próprios limites, que renova e singulariza o seu educar. Docência artística, portanto, nos convoca a trabalhar na materialidade da cultura. [...] Assumir o risco de educar sem deixar que as ilusões fechem os horizontes sociais, nos empurrem para o conservadorismo ou violentam a heterogeneidade da infância (CORAZZA, 2006, p. 81).

(Re) significar a docência e sua relação com as infâncias e os processos de alfabetização leva-nos a valorizar a organização de rotinas escolares, como tempos-espaços que favoreçam, coerentemente, as linguagens, oral e escrita, com as singularidades das crianças e de suas infâncias.

\section{Considerações Finais}

Buscamos compreender, a partir do material para formação docente, como o PNAIC orienta o ensino e o aprendizado da leitura e da escrita, no primeiro ano do ensino fundamental, e como as crianças e as infâncias são vistas nesse processo. Em decorrência desse objetivo, pudemos observar concepções que o Programa expressa sobre o professor e sua formação. Constatamos que esse Programa se fundamentou, principalmente, no argumento dos “direito(s) de aprendizagem" das crianças. Partindo do exposto e considerando o conjunto de aspectos decorrentes deste trabalho, da configuração textual e dos indícios dos cadernos de formação, podemos apresentar algumas reflexões críticas em relação ao PNAIC:

1) Os direitos de aprendizagem das crianças preconizados pelo PNAIC, em seus Cadernos, podem ser interpretados como deveres de aprendizagens, o que, também, subentendem deveres de ensinar para os professores, na medida em que sinalizam tanto o que, como e quando ensinar, quanto o que, como e quando as crianças devem aprender.

2) A concepção da linguagem apresentada é fragmentada e normativa, configurando-se por meio dos eixos estruturantes da língua (leitura; produção de textos escritos; oralidade; análise 
linguística: discursividade, textualidade e normatividade; e análise linguística: apropriação do sistema de escrita alfabética). Sua organização metodológica transforma o conhecimento e a aprendizagem num processo linear, cumulativo, gradual e fragmentado.

3) A proposta de formação para o ensino da língua portuguesa dosa e controla o ensino e a aprendizagem, por meio do trinômio introduz̧ir, aprofundar e consolidar. Tal constatação reforça a tentativa hegemônica de conduzir as práticas docentes, bem como de regular os tempos de aprendizagem das crianças. Adota-se um discurso aberto ao diálogo, porém apresenta-se fechado, quando, por meio de currículo estático, universaliza os tempos de aprendizagem de todas as crianças, a organização do trabalho docente, e quando não aborda as complexidades e singularidades/realidades de cada escola.

4) O planejamento do processo de alfabetização e de ensino/aprendizagem da língua portuguesa é voltado, exclusivamente, para os eixos direcionadores da língua. Há um silêncio, ensurdecedor, sobre as características próprias das crianças de seis anos, em relação ao modo de organização do tempo e do espaço escolar, as manifestações de linguagens e sua incorporação nas rotinas escolares, contribuindo para a desvalorização do brincar e o distanciamento das necessidades das crianças. Sendo assim, na proposta do PNAIC, não se incentiva o trabalho docente com outras linguagens; o foco está restrito na língua portuguesa.5) A base da proposta do PNAIC é que as crianças têm direitos. No entanto, seu principal direito, o de brincar, está sendo descaracterizado, devido às exigências do ensino fundamental. Isto é, as brincadeiras e os jogos são interpretados como ferramentas, predominantemente, voltadas para o ensino dos conteúdos. Nessa perspectiva, o brincar como atividade principal da infância, mesmo sendo defendido nos cadernos da formação do PNAIC, está perdendo seu espaço para atividades dirigidas ao processo de alfabetização e de letramento, restringindo sua função potencializadora do desenvolvimento integral da criança, bem como a capacidade de as crianças interagirem e lerem o mundo, a construção da linguagem e do conhecimento, como se o brincar fosse algo desconectado desses aspectos.

5) O PNAIC não considera o professor, em seu processo autoral de criação e liberdade de ensinar, pois há um modelo a ser seguido. Na mesma direção, não considera as crianças, reais, como protagonistas, como sujeitos de direitos, uma vez que desconsideram suas singularidades de aprendizagem, no processo de leitura e escrita.

Mediante as reflexões aqui apresentadas faz-se necessária a continuidade dos estudos e das pesquisas, bem como a ampliação de debates entre educadores, universidades e governo, nas áreas de formação de professores, leitura e escrita, sobretudo, nas temáticas que envolvem as crianças e suas infâncias. O processo de formação de professores alfabetizadores não pode ser considerado como manual de ensino a ser adquirido, voltado apenas para aplicar novas e controladas estratégias, no processo 
de alfabetização das crianças.

Os professores precisam ser evidenciados nas propostas de formação. Isso quer dizer que devem participar, ativamente, de sua formulação, criação, definindo conteúdos, estratégias, ampliando sua formação, de forma coletiva e contextualizada, construindo identidades profissionais. Da mesma forma, como profissional que é, precisa de apoio, recursos, plano de valorização de cargos e salários justos, dignos, adequados ao teor de seu trabalho e liberdade para a formação em serviço, na escola, refletindo e construindo, com seus pares, a partir do contexto e das especificidades de sua escola, um projeto político-pedagógico singular.

A qualidade da educação depende da valorização das ações e da complexidade de cada escola do país, como um contexto único de saberes e práticas, reconhecendo o caráter heterogêneo e plural das ações, vivências e experiências realizadas pelos docentes, a partir das necessidades da escola, e, não, por meio da hegemonia de resultados de avaliações externas que avaliam a aprendizagem dos alunos, considerando-se as práticas sugeridas nos processos de formação. Por isso, uma proposta homogênea (nacional!?) não atende os contextos locais e as heterogeneidades de cada realidade educacional.

Mais do que reconhecer a importância do professor e de sua formação, a partir de cada realidade, é imprescindível enxergar a criança nesse contexto, é preciso para ela olhar, cuidadosa e humanamente. Esse olhar diz respeito ao conhecer, vivenciar, experimentar, aproximar-se, compreendê-la como ativa no processo de construção do conhecimento, como sujeito de direitos, que tem voz e vez, como ser ativo e criativo que produz cultura. Portanto, não faz sentido uma proposta de formação de professores de crianças que não as concebam dessa maneira. Não faz sentido defender direitos de aprendizagem das crianças, e desconsiderar aqueles que são essenciais em sua vida.

Esse processo de aquisição da leitura e escrita, para as crianças de seis anos, enviesado pelo tempo certo de aprender e por meio de práticas descontextualizadas do movimento da pluralidade de linguagens existentes, como expressões das crianças, poderá trazer consequências desastrosas para seu desenvolvimento. Por exemplo, a negação ou a desvalorização de tempo para se viver a infância, e a (re)produção de mais fracassos na escola.

Consideramos que nossa pesquisa traz importantes contribuições para fomentar o debate e subsidiar profícuas reflexões, em futuros estudos, sobre os processos de formação continuada de docentes, leitura e escrita e, principalmente, sobre as crianças. Crianças que precisam ser olhadas e consideradas, a partir de suas condições históricas, seus direitos essenciais, sua singularidade, seus desejos, suas dúvidas, seus sonhos, seus movimentos. Crianças reais! 


\section{Referências}

ABRAMOVAY, Miriam; KRAMER, Sônia. Alfabetização na Pré-Escola: exigência ou necessidade. Caderno de Pesquisa, São Paulo, vol. 52, 103-107, fev. 1985.

BAKHTIN, M.; VOLOCHÍNOV, V. N. Marxismo e filosofia da linguagem. 7. ed. Tradução de Michel Lahud e Yara Frateschi Vieira. São Paulo: Hucitec, 1995.

BRASIL. Ministério da Educação. Secretaria de Educação Básica. Diretoria de Apoio à Gestão Educacional. Pacto nacional pela alfabetização na idade certa: Formação de professores no Pacto Nacional pela Alfabetização na Idade Certa. Brasília: MEC, SEB, 2012.

BRASIL. Ministério da Educação. Secretaria de Educação Básica. Diretoria de Apoio à Gestão Educacional. Pacto nacional pela alfabetização na idade certa: Currículo na alfabetização: concepções e princípios. Ano 1: Unidade 1. Brasília: MEC, SEB, 2012a.

BRASIL. Ministério da Educação. Secretaria de Educação Básica. Diretoria de Apoio à Gestão Educacional. Pacto nacional pela alfabetização na idade certa: Planejamento escolar: alfabetização e ensino da língua portuguesa. Ano 1: Unidade 2. Brasília: MEC, SEB, $2012 \mathrm{~b}$.

BRASIL. Ministério da Educação. Secretaria de Educação Básica. Diretoria de Apoio à Gestão Educacional. Pacto nacional pela alfabetização na idade certa: Ludicidade na sala de aula. Ano 1: Unidade 4. Brasília: MEC, SEB, 2012d.

CORAZZA, Sandra Mara. Novos Lugares do Infantil. In: DALPIAZ, Sonia; GURSKI, Roselene; VERDI, Marcelo Spalding (Orgs.). Cenas da infância atual: a família, a escola e a clínica. Ijuí: Ed. Unijuí, 2006.

FONTANA, Roseli e CRUZ, Nazaré. Psicologia e trabalho pedagógico. São Paulo: Atual, 1997.

KLEIN, Sylvie Bonifácio. Ensino fundamental de nove anos no município de São Paulo: um estudo de caso. 2011. 233f. Dissertação (Mestrado em Educação) - Faculdade de Educação, Universidade de São Paulo, São Paulo, 2011.

KRAMER, Sônia. A infância e sua singularidade. In: BEAUCHAMP, Jeanete; PAGEL, Sandra Denise. NASCIMENTO, Aricélia Ribeiro do (orgs). Ensino fundamental de nove anos: orientações para a inclusão da criança de seis anos de idade. Brasília: FNDE, Estação Gráfica, 2007.

LÜDKE, Menga; ANDRÉ, Marli E. D. A. Pesquisa em educação: abordagens qualitativas. 2. ed. Rio de Janeiro: E.P.U., 2013.

PROENÇA, Maria Alice de Rezende. A rotina como âncora do cotidiano na Educação Infantil. Revista Pátio Educação Infantil, Porto Alegre, n. 4, p.13-15, 04 abr. 2004.

RESENDE, Valéria Aparecida Dias Lacerda de. Análises dos pressupostos de linguagem nos cadernos de formação em língua portuguesa do pacto nacional pela alfabetização na idade certa - PNAIC. Tese (Doutorado em Educação). Faculdade de Filosofia e Ciências, Universidade Estadual Paulista "Júlio de Mesquita Filho", Marília, 2015. 
VIGOTSKI, Lev Seminovich. Imaginação e criação na infância. Tradução Zoia Prestes. São Paulo: Ática. 2009.

VIGOTSKI, Lev Seminovich. A construção do pensamento e da linguagem. Tradução Paulo Bezerra. São Paulo: Martins Fontes. 2000. 